\title{
Laparoscopic stapler appendectomy in pediatric patients
}

\author{
Daniela Dobritoiu', Alin Stoica', Simona-Gabriela Tudorache ${ }^{1,2}$, \\ Laura-Mihaela Ion ${ }^{1,2}$, Iunia-Carla Floricel ${ }^{2}$ \\ ${ }^{1}$ Ponderas Academic Hospital, Bucharest, Romania \\ ${ }^{2}$ Faculty of Medicine, "Titu Maiorescu" University, Bucharest, Romania
}

\begin{abstract}
Introduction. Acute appendicitis is the most frequent cause of surgical abdominal pain in children. There are multiple variants of surgical treatment of acute appendicitis, including laparoscopic stapler appendectomy.

Aim. We proposed to present our experience regarding laparoscopic stapler appendectomy as an alternative treatment method in children diagnosed with appendicitis.

Material and method. In this retrospective descriptive, observational study we analyzed the data of children admitted with appendicitis to Ponderas Academic Hospital between January 2018 and October 2020.

Results. 78 laparoscopic appendectomies were performed in children with ages of 3 to 16 years old. Of these, 70 were performed using mechanical suturing devices. Time of surgery was 77 minutes in 2018, 76 minutes in 2019 and 91 minutes in 2020. In 2020 the number of complicated appendicitis was double than in 2019 and six times higher than in 2018 but time of surgery was smaller in these cases in 2020 with longer hospital stay.

Conclusions. In 2020 we observed that was a smaller number of patients operated, with higher time of surgery, length of hospital stay, more complicated appendicitis (regarding drainage usage) but with smaller time of surgery in these complicated cases which indicates the effectiveness of using the stapler.

Keywords: stapler appendectomy, minimally invasive surgery, abdominal pain, children,
\end{abstract} adolescent

\section{INTRODUCTION}

Acute appendicitis is the most frequent cause of surgical abdominal pain in children. 1-8 \% of children evaluated for abdominal pain in the emergency room turn out to have appendicitis and the incidence is highest in the second decade of life (10-18 years old) (1).

Abdominal pain that migrates from the upper regions to the right lower quadrant often in the first 24 hours of the onset, that can associate focal abdominal tenderness, anorexia or vomiting and low grade fever $\left(38-38.5^{\circ} \mathrm{C}\right)$ are the classic symptoms in children with acute appendicitis but we rarely encounter all three elements especially in those younger than five years. Laboratory tests (white blood cell count, Creactive protein, urine analysis) and imaging (ultrasound, computed tomography) can help differentiate appendicitis form other causes of abdominal pain in children but usually close clinical reevaluation by the same pediatric surgeon should clear the doubts.

Although there are some papers published that advocate antibiotic as the sole treatment for uncomplicated appendicitis in children, appendectomy remains the treatment of choice for many caregivers, due to high recurrence rates of medical treatment alone (2-5).

To date there are multiple variants of surgical treatment of acute appendicitis from the classic right lower quadrant McBurney incision to laparoscopic appendectomy, laparoscopic assisted or single port appendectomy, each with its specific advantages and disadvantages.

A critical step when performing appendectomy is sealing the appendicular stump, its incomplete closure can lead to serious complications. While in open approach, simple or double ligation of the appendicu- 
lar base with or without burying the appendix stump into the caecum is performed, for laparoscopic appendectomy multiple options are available: preformed loops with extracorporeal knots, handmade intracorporeal knots, non-absorbable polymer clips hem-o lock, titanium clips, transecting with LigaSure or with bipolar cautery, mechanical suturing devices - staplers. There is still controversy regarding witch method is best and literature provides contradictory data (4). It is clear that the ideal method should be safe, applicable, easy to use and cost efficient (5). All methods are reported as safe but some prolong the operation and require advanced skills - handmade knots, and some are not applicable if the base of the appendix is too large or too inflamed (6-9).

Since almost 60 years ago, when Hopkins invented the rod lens system and Semm (10) the abdominal gas insufflating and pressure monitoring machine, laparoscopic surgery has known great evolution, and has become standard of care for many different pathologies, especially in adults. Acceptance of minimally invasive surgery in children has been slow due to many reasons like the lack of adequate size instruments, small working space, lack of experience and high costs of the equipment (11). Many of these problems disappeared over time - there are various small instruments available now, experience has been gained mostly with the help of adult general surgeons so now, in many pediatric hospitals, mostly in teaching hospitals, children can benefit of laparoscopic and thoracoscopic surgery, for a great number of pathologies (12).

Since appendicitis in the most frequent cause of abdominal pain in children (13), it is easily understood that appendicitis treatment is already shifting form open surgery to minimally invasive techniques in many centers and without increasing morbidity or mortality. Moreover, there are a lot of papers published that show that in experienced centers, complication rate is even lower in laparoscopic appendectomy when compared to classical appendectomy in children $(14,15)$.

Staplers are commonly used intra-operatively during small bowel resections or in colorectal surgery. First use in laparoscopic appendectomy was reported over 30 years ago and since then their use was increasingly reported with great results (9). These staplers have an integral knife which, as the stapler deploy, cuts through the bowel and maintains the aseptic field, prevents the spilling of intestinal content in the peritoneal cavity. These devices are also safe to use when the base of the appendix is enlarged by significant inflammatory process. These are the reasons why we found them useful in the resection of the appendix.
Over the time, many variants of minimally invasive appendectomy emerged - laparoscopic assisted, full laparoscopic or single port appendectomy, with small differences in outcomes $(16,17)$, but each its specific instruments and learning curve. We believe that as long as the whole abdominal cavity is inspected and cleaned, the exact procedure is a matter of personal preference and experience of the surgeon.

\section{AIM}

The aim of this paper is to present our experience regarding laparoscopic stapler appendectomy as an alternative treatment method in children diagnosed with appendicitis, taking into account that in Romania few hospitals perform routine laparoscopic emergency appendectomies in children and even fewer have access to advanced sealing devices (staplers).

\section{MATERIALS AND METHOD}

After approval of the study by the institutional review board (document 173/19.06.2021), we selected the pediatric patients who presented to our hospital, Ponderas Academic Hospital, with abdominal pain and who, after being diagnosed with appendicitis, were treated by laparoscopic appendectomy between January 2018 and October 2020.

The inclusion criteria were: abdominal pain with tenderness on palpation, with or without associated symptoms like vomiting, nausea, fever; inflammatory biological syndrome: neutrophilia, elevated levels of serum C protein; signs of appendicitis on ultrasound abdominal examination - free peritoneal fluid, increased diameter of the appendics, with or without intraluminal coprolite.

11 patients that proved to have other causes for the abdominal pain (gastroenteritis, ovarian torsion, constipation) were excluded from the study. Patients that were diagnosed with appendicular abscess and were treated in a staged manner (first oral or intravenous antibiotics and then delayed appendectomy at 4 to 6 weeks) were only included in the study when appendectomy was performed.

Upon admission, informed consent regarding medical treatment and surgery was obtained from primary caregivers - both parents.

This is an observational, descriptive retrospective study and we analyzed patient's demographic data collected from the hospital's data base - (age, sex), the time of surgery, the rate of intraoperative complications (trocar insertion related intraabdominal organ injury, bleeding, conversion rate) and associated pathology observed at the time of laparoscopy (inguinal 
hernia, Meckel's diverticulum, ovarian cyst, urachal cyst). Their postoperative evolution was observed in terms of length of hospital stay, necessity and duration of peritoneal drainage, and cosmetic result.

Statistical data of the 78 selected patients was analyzed following the biostatistical recommendations in the current medical practice using Microsoft Excel (18).

The number of cases per year reported here is not very high which can be due, on one hand, to the careful selection of patients, after thorough clinical and non-clinical evaluation, and on the other hand to the fact that our hospital is a private hospital and general costs may limit addressability.

\section{RESULTS}

Because there are few cases of appendectomy without stapler and this fact does not allow us a comparison, we performed a retrospective, observational study on cases of laparoscopic appendectomy performed in the period 2018-2020 and we consider this to be a limit of our study.

Between January 2018 and October 2020, we performed 78 laparoscopic appendectomies, 25 in 2018, 30 in 2019 and 23 in the first 10 months of 2020 (figure 1).

We analyzed demographic data collected from the hospital's data base (age, sex), the time of surgery, the rate of intraoperative complications and associated pathology observed at the time of laparoscopy. Their postoperative evolution was observed in terms of length of hospital stay, necessity and duration of peritoneal drainage, and cosmetic result.

Figure 1 presents the distribution of patients per year.

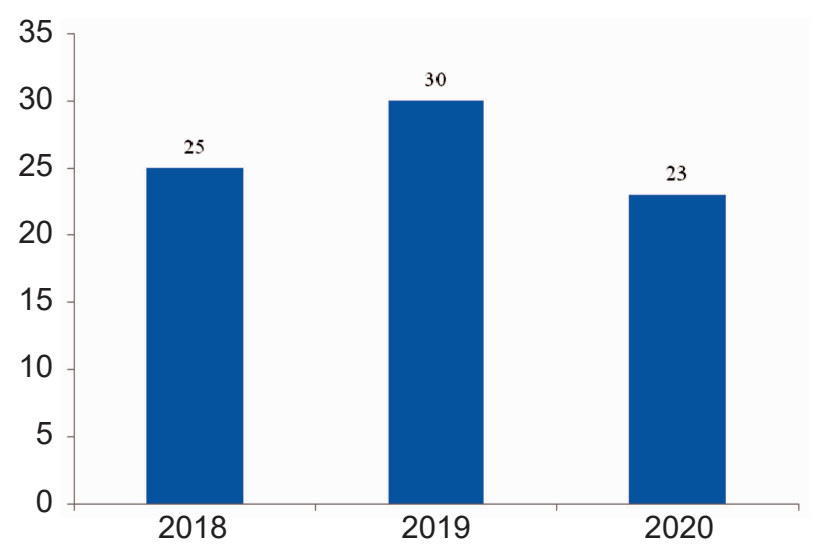

FIGURE 1. Number of patients per year

Regarding gender distribution, 43 (55\%) were male and $35(45 \%)$ were female, with a male to female ratio of 1.2:1 (figure 2).

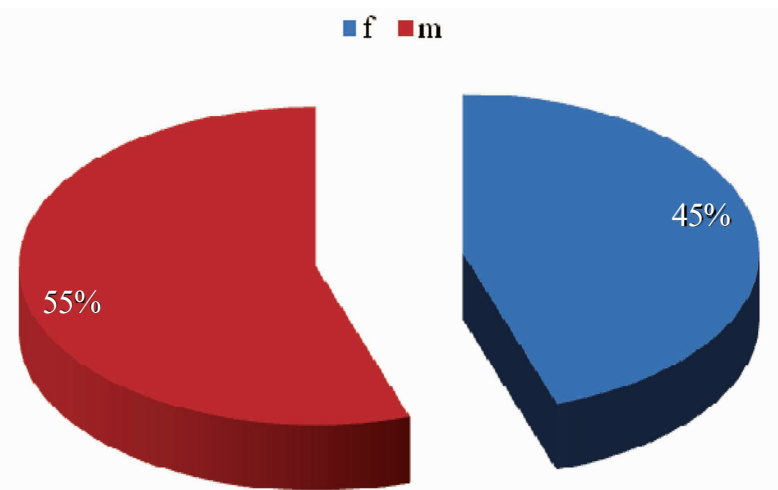

FIGURE 2. Patients distribution by gender

The patients included in the study were 3-16 years old, with an average age of $9.84 \pm 3.25$. Distribution of patients in the study group by age shows an incidence peak in the age group 9-11 years old (37.17\%) (figure 3).

In the study group of 78 patients, 64 patients $(82 \%)$ were diagnosed with acute appendicitis and were taken to the OR in the first few hours after the hospital admission. The other 14 patients $(18 \%)$ were considered to have chronic, recurrent or appendicitis and received surgical treatment in a scheduled manner.

In all 78 patients in the study group, we performed three port laparoscopic appendectomies and there were no conversions and no need for no additional working ports. Mechanical suturing devices were used in most of the patients in the study group, (70/78, $89.74 \%$ ) and intra-corporeal knots in the rest of them $(8 / 78,10.25 \%)$. From 70 appendectomies that were performed using mechanical suture, 20 were performed in 2018, 27 in 2019 and 23 in 2020. Appendectomy using intra or extracorporeal knots were only performed the previous years: 3 in 2019 and 5 in 2018.

Mean time of surgery was $79.22+/-30.36$ minutes $(30-180)$ for all patients, with 6 operations taking longer than 2 hours (120 min). These were cases of complicated appendicitis with extensive peritoneal, appendicular and adjacent intestinal loops inflammation. When grouped by year and total operating time, we noticed a slight increase in the duration of surgery in the patients treated during the year 2020 (figure 4).

There was one (1.28\%) intraoperative complication - small bowel tear during initial port placement which was managed by laparoscopic small intestine suturing.

At the time of laparoscopic abdominal inspection there were 2 boys and 2 girls who proved to have unilateral patent peritoneo-vaginal communication. Of these, only one girl remained asymptomatic and 


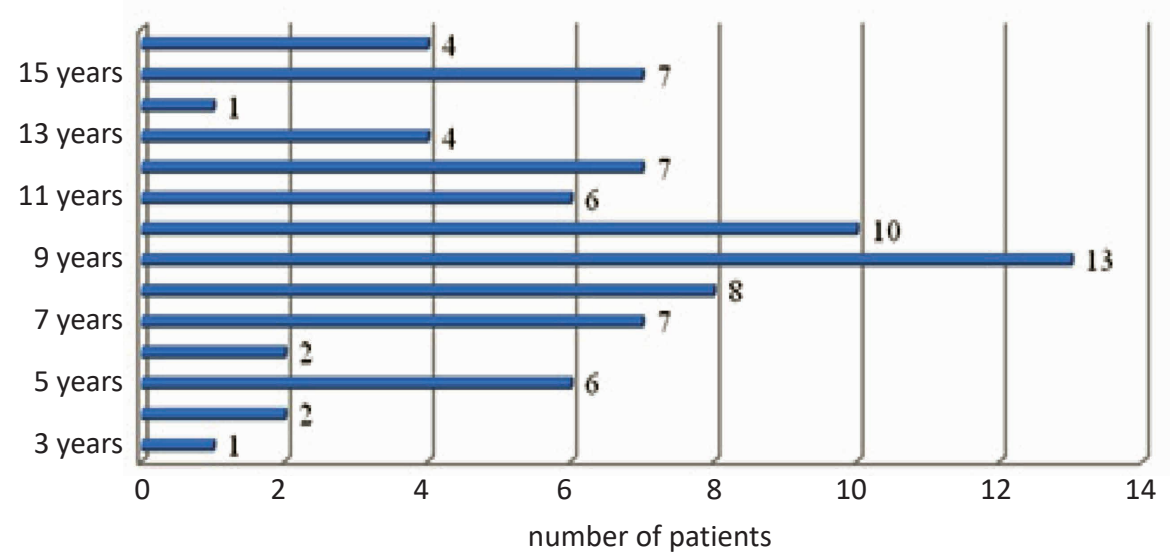

FIGURE 3. Distribution of patients by age at the time of surgery

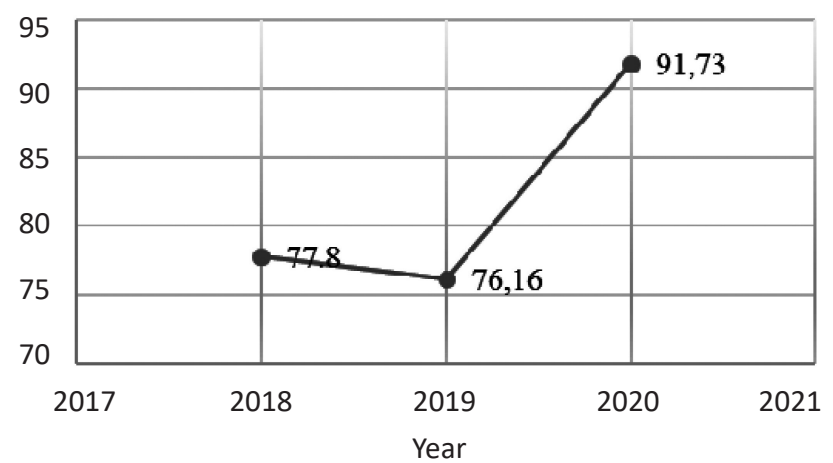

FIGURE 4. Time of surgery (minutes) - mean per year

TABLE 1. Time of surgery

\begin{tabular}{|l|c|c|c|c|c|}
\hline & $\begin{array}{c}\text { Number } \\
\text { of } \\
\text { patients }\end{array}$ & $\begin{array}{c}\text { Minimum } \\
\text { operating } \\
\text { time }\end{array}$ & $\begin{array}{c}\text { Maximum } \\
\text { operating } \\
\text { time }\end{array}$ & $\begin{array}{c}\text { Mean } \\
\text { operating } \\
\text { time (min) }\end{array}$ & ST dev \\
\hline 2018 & 25 & 30 & 120 & 77.8 & 22.03 \\
\hline 2019 & 30 & 30 & 150 & 76.16 & 32.55 \\
\hline 2020 & 23 & 45 & 180 & 91,73 & 35.84 \\
\hline Total & $\mathbf{7 8}$ & $\mathbf{3 0}$ & $\mathbf{1 8 0}$ & $\mathbf{7 9 . 2 2}$ & $\mathbf{3 0 . 4 6}$ \\
\hline
\end{tabular}

did not have an inguinal hernia repair as the other children did. Two other boys had Meckel diverticulum that was identified at ileum inspection. These were resected later on, although they remained free of symptoms. In total, 6 (7.69\%) patients had associated intraabdominal pathology that was observed during laparoscopy.

For laparoscopic stapler appendectomy we used 12 and $5 \mathrm{~mm}$ trocars with one umbilical optic port $(12 \mathrm{~mm})$ and two working sites $(5 \mathrm{~mm}$ - one in the left iliac fossa and one 2-3 cm above pubic bone, 1 $\mathrm{cm}$ to the left from the midline). Even though, in order to perform stapler appendectomy, the $12 \mathrm{~mm}$ port is necessary, local anesthetic infiltration at port site at the end of the surgery kept minimal complaints about postoperative pain.

We decided to leave in place a peritoneal drainage in 20 patients ( $25.6 \%$ of the study group), which was functional for 12 hours in 3 patients, 24 hours in 9 patients, 48 hours in 6 patients and 72 hours in only 2 patients. If we consider the year of the surgery, 2 patients needed drainage in 2018, 6 in 2019 and 12 patients in 2020 (figure 5). One patient of the 8 in which intra-corporeal knots were used for the sealing of the appendicular stump maintained a high quantity of free peritoneal fluid until after day 10 post operatively, that resolved afterwards uneventfully.

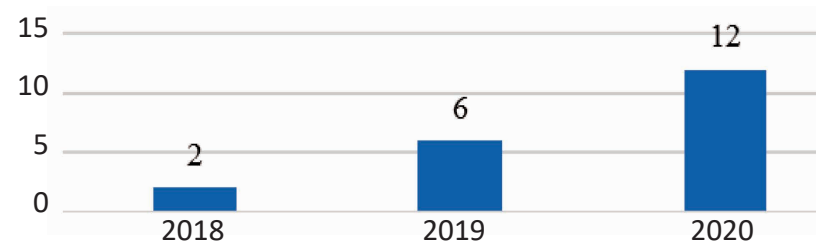

FIGURE 5. Distribution of number of patients with drainage grouped by year of surgery

TABLE 2. Number of patients with peritoneal drainage by year, mean surgery time, mean time before extraction of the drainage, mean hospital stay

\begin{tabular}{|c|c|c|c|c|}
\hline Year & $\begin{array}{c}\text { Number } \\
\text { of } \\
\text { patients }\end{array}$ & $\begin{array}{c}\text { Mean time } \\
\text { of surgery } \\
\text { (minutes) }\end{array}$ & $\begin{array}{c}\text { Mean time } \\
\text { of peritoneal } \\
\text { drainage } \\
\text { (hours) }\end{array}$ & $\begin{array}{c}\text { Mean } \\
\text { hospital } \\
\text { stay } \\
\text { (hours) }\end{array}$ \\
\hline 2018 & 2 & 100 & 24 & 60 \\
\hline 2019 & 6 & 124 & 28 & 60 \\
\hline 2020 & 12 & 109 & 38.18 & 74.18 \\
\hline total & 20 & 113.06 & 33.47 & 68.2 \\
\hline
\end{tabular}

We observed that in 2020, despite the fact that the mean time of peritoneal drainage and mean hospital stay are higher, associated with complicated appendicitis, the mean time of surgery is smaller than in 2019 and similar to 2018 .

The shortest hospital stay was 24 hours, but most of the patients remained in hospital for 48 hours, with a maximum of 120 hours (figure 6, table 3), in 2020 is the highest hospital stay. 


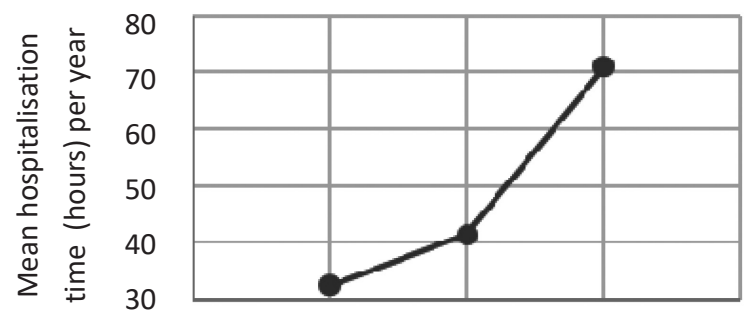

FIGURE 6. Length of hospital stay by year of surgery

TABLE 3. Length of stay

\begin{tabular}{|l|c|c|c|c|c|}
\hline & $\begin{array}{c}\text { Number } \\
\text { of } \\
\text { patients }\end{array}$ & $\begin{array}{c}\text { Mean } \\
\text { hospital } \\
\text { stay (h) }\end{array}$ & $\begin{array}{c}\text { Minimum } \\
\text { hospital } \\
\text { stay (h) }\end{array}$ & $\begin{array}{c}\text { Maximum } \\
\text { hospital } \\
\text { stay (h) }\end{array}$ & stdev \\
\hline 2018 & 25 & 32.44 & 24 & 72 & 13.26 \\
\hline 2019 & 30 & 41.4 & 24 & 72 & 15.05 \\
\hline 2020 & 23 & 70.95 & 48 & 120 & 21.07 \\
\hline total & $\mathbf{7 8}$ & $\mathbf{4 7 . 2 4}$ & $\mathbf{2 4}$ & $\mathbf{1 2 0}$ & $\mathbf{2 2 . 7 9}$ \\
\hline
\end{tabular}

Standard deviation is highest in 2020 - we can think that there are more patients with operating time in the extremes - away from the mean by year.

We noticed the increase in mean time of surgery over the three years period (figure 4, table 1), which is not consistent with a normal learning curve but we correlate the increase of time of surgery with the complexity of cases, as we can also notice an increase in length of hospital stay and the need for peritoneal drainage (table 2) as markers of complicated appendicitis. But if we look at the mean time of surgery, over the three years of the study, only in patients that needed drainage, as a sign for complicated appendicitis, we notice that is was smaller in 2020 than in 2019 and similar to the year 2018 (table 2).

We consider that a laborious surgery request more time and also more days in the hospital. This also correlates with the fact that, in the beginning of SARS-CoV-2 pandemic, people came for medical advice later than usual.

In terms of cosmetic results, all patients and caregivers declared themselves satisfied with the appearance (figure 7). The trans-umbilical or semicircular supra-umbilical incision used for de $12 \mathrm{~mm}$ port usually heals well and the scar is easily hidden.

\section{DISCUSSIONS}

As Rogers et al. emphasizes in his study, acceptance of minimally invasive surgery in children has been slow due to many reasons like the lack of adequate size instruments, small working space, lack of experience and high costs of the equipment (11). Since the protocol in our hospital is laparoscopic appendectomy, we could not perform a comparative study between open versus laparoscopic appendec-

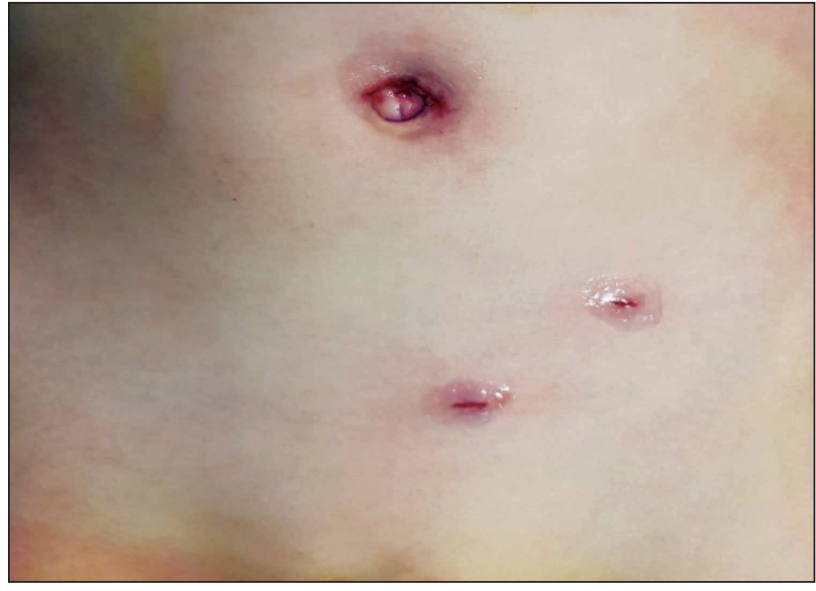

FIGURE 7. Postoperative aspect of stapler appendectomy sealed with skin glue

tomy as Mattei et al. and Jaschinski et al. made in their studies. Other methods of sealing the appendicular stump were used only in few patients in our hospital, so a comparative study between various methods of sealing the appendicular stump as postulated by Beldi et al., could not be done $(19,20,21)$. We think that our experience is important to be exposed since this method is not used in current practice in the Romanian children's hospitals In our series, we only performed laparoscopic appendectomy and had no wound infection, no post operatory occlusion syndrome, and a reasonable length of in hospital stay.

From 78 appendectomies performed in the three years of the study, in 8 cases we used intra-corporeal knots for sealing the appendicular stump and all the appendectomies performed in 2020 when we have had the most complicated number of cases were done with stapler. As Delibegović et al. say in their study, there is still controversy regarding witch method is best and literature provides contradictory data (6). The ideal method should be safe, applicable, easy to use and cost efficient (7), as Makaram et al. concluded.

Although Dunn et al. find that the peak incidence occurs between ages 11 and 12 (22) in our study the groups of 9 and 10 years old have had the highest number of patients.

From the gender perspective, we found that the male:female ratio was 1,2:1 as Salö et al. evaluate in his study, there is a higher incidence in boys and also in his study boys had a higher frequency of perforation even though their time to appendectomy equaled that of girls (23).

Even though our team is mainly comprised of young surgeons, our operating time is comparable with what we can find in the literature. For example, Lukish et al. published an operating time for laparoscopic stapler appendectomy of 74.5 minutes, in a tertiary children hospital in United States (24). 
In 4 cases, during laparoscopy we found patent of processus vaginalis and we decided not to close them because of a possible septic complication and as Centeno-Wolf et al. says in his article, only $10 \%$ of these children later develop a hernia. We follow up all these cases with ultrasound postoperative (25).

Because we are using the stapler for sealing the appendicular stump, we needed to insert a $12 \mathrm{~mm}$ trocar through the umbilicus and we found it difficult in smaller children, but as Beldi et al. says in his study the suture is even on both sides, is very time saving and the risk of consecutive abdominal collection is reduced (21). These devices are also safe to use when the base of the appendix is enlarged by significant inflammatory process.

Song et al. found that there seems to be little evidence to support peritoneal drain insertion after appendectomy, even in perforated appendicitis cases (26). As Aneiros Castro et al. say in their study, this is an endless controversy and prospective randomized controlled studies are still necessary to verify this hypothesis (27). In patients with complicated appendicitis included in our study, we decided to leave in place a peritoneal drainage.

The mean hospital stay varied from $32 \mathrm{~h}$ in 2018 to $70 \mathrm{~h}$ in 2020 compared to $58 \mathrm{~h}$ which is the mean total hospital stay observed by Grewal et al. in his study (28). We think that this increase is due to the fact that in 2020 there were more complicated cases.

It is important to notice that despite the fact that in 2020 we observed higher time of surgery and hospital stay, the mean time of surgery in the cases that needed drainage was smaller in 2020 than the previous year, and similar to 2019. As Takami et al. say,

\section{REFERENCES}

1. Wesson DE, Brandt ML. Acute appendicitis in children: Clinical manifestations and diagnosis. Available at: https://www.uptodate. com/contents/acute-appendicitis-in-children-clinical-manifestationsand-diagnosis.

2. Minneci PC, Mahida JB, Lodwick DL, Sulkowski JP, Nacion KM, Cooper JN, Ambeba EJ, Moss RL, Deans KJ. Effectiveness of Patient Choice in Nonoperative vs Surgical Management of Pediatric Uncomplicated Acute Appendicitis. JAMA Surg. 2016 May 1;151(5):408-15.

3. Georgiou R, Eaton S, Stanton MP, Pierro A, Hall NJ. Efficacy and Safety of Nonoperative Treatment for Acute Appendicitis: A Meta-analysis. Pediatrics. 2017 Mar;139(3):e20163003.

4. Huang L, Yin Y, Yang L, Wang C, Li Y, Zhou Z. Comparison of Antibiotic Therapy and Appendectomy for Acute Uncomplicated Appendicitis in Children: A Meta-analysis. JAMA Pediatr. 2017 May 1;171(5):426-434.

5. Steiner Z, Buklan G, Stackievicz R, Gutermacher M, Litmanovitz I, Golani G, Arnon S. Conservative treatment in uncomplicated acute appendicitis: reassessment of practice safety. Eur J Pediatr. 2017 Apr;176(4):521-527.

6. Delibegović S, Karabeg R, Simatović M. Securing the base of the appendix during laparoscopic appendectomy. Med Glas (Zenica). 2020 Aug 1;17(2):252-255 better outcomes in minimally invasive appendectomy are more obvious when we take into account the complicated appendicitis (late diagnosis, advanced disease - extensive inflammation of the peritoneal cavity (15).

The smaller number of patients in 2020 can be also related to the COVID-19 pandemic as Rosenthal et al. observed that acute appendicitis presentations decreased significantly during the COVID-19 pandemic (29). In addition the higher number of complicated appendicitis we think, can also be associated with the pandemics. On the contrary, Ceresoli et al. found that admissions for complicated acute appendicitis did not change, while there was a significant reduction of both admissions for non-complicated acute appendicitis and negative appendectomy rate during the pandemic period (30).

The limitation of this study is the lack of two comparable groups that would have permitted to draw firmer conclusion.

\section{CONCLUSIONS}

In 2020 we observed that were a smaller number of patients operated, with higher length of hospital stay, more complicated appendicitis (regarding drainage usage), but with shorter time of surgery in these complicated cases, which indicates the effectiveness of using the stapler. We think that a prospective comparative study is needed to prove this but we consider that at least in complicated appendicitis the stapler should be used to seal the appendicular stump in all pediatric surgery centers as a protocol.

7. Makaram N, Knight SR, Ibrahim A, Patil P, Wilson MSJ. Closure of the appendiceal stump in laparoscopic appendectomy: A systematic review of the literature. Ann Med Surg (Lond). 2020 Aug 4; 57:228-235.

8. Lasek A, Wysocki M, Mavrikis J, Myśliwiec P, Bobowicz M, Dowgiałło-Wnukiewicz N, Kenig J, Stefura T, Walędziak M, Pędziwiatr M; Pol-LA (Polish Laparoscopic Appendectomy) Collaborative Study Group. Comparison of stump closure techniques during laparoscopic appendectomies for complicated appendicitis - results from Pol-LA (Polish laparoscopic appendectomy) multicenter large cohort study. Acta Chir Belg. 2020 Apr;120(2):116-123.

9. Mayir B, Ensari CÖ, Bilecik T, Aslaner A, Oruç MT. Methods for closure of appendix stump during laparoscopic appendectomy procedure. Ulus Cerrahi Derg. 2015 Aug 18;31(4):229-31.

10. Litynski GS. Kurt Semm and an automatic insufflator. JSLS. 1998 Apr-Jun;2(2):197-200.

11. Rogers DA, Lobe TE, Schropp KP. Evolving uses of laparoscopy in children. Surg Clin North Am. 1992 Dec;72(6):1299-313.

12. Zitsman JL. Pediatric minimal-access surgery: update 2006. Pediatrics. 2006 Jul;118(1):304-8.

13. Kim JS. Acute abdominal pain in children. Pediatr Gastroenterol Hepatol Nutr. 2013 Dec;16(4):219-24. 
14. Barka S, Shoaib M, et al. Compare the outcomes of laparoscopic appendectomy versus conventional open appendectomy. Medical Forum Monthly. 2020;31(8).

15. Takami T, Yamaguchi T, Yoshitake H, Hatano K, Kataoka N, Tomita M, Makimoto S. A clinical comparison of laparoscopic versus open appendectomy for the treatment of complicated appendicitis: historical cohort study. Eur J Trauma Emerg Surg. 2020 Aug;46(4):847-851.

16. Binet A, Braïk K, Lengelle F, Laffon M, Lardy H, Amar S. Laparoscopic one port appendectomy: Evaluation in pediatric surgery. J Pediatr Surg. 2018 Nov;53(11):2322-2325.

17. Kang BM, Choi SI, Kim BS, Lee SH. Single-port laparoscopic surgery in uncomplicated acute appendicitis: a randomized controlled trial. Surg Endosc. 2018 Jul;32(7):3131-3137.

18. Seritan GC. Guidelines for small size samples biostatistics in current medical practice. Institute of Electrical and Electronics Engineers Inc., 2019, lasi, Romania.

19. Mattei P. Minimally invasive surgery in the diagnosis and treatment of abdominal pain in children. Curr Opin Pediatr. 2007 Jun; 19(3):338-43.

20. Jaschinski T, Mosch CG, Eikermann M, Neugebauer EA, Sauerland S. Laparoscopic versus open surgery for suspected appendicitis. Cochrane Database Syst Rev. 2018 Nov 28;11(11):CD001546.

21. Beldi G, Vorburger SA, Bruegger LE, Kocher T, Inderbitzin D, Candinas D. Analysis of stapling versus endoloops in appendiceal stump closure. Br J Surg. 2006 Nov;93(11):1390-3.

22. Dunn JCY. Appendicitis. In: Coran AG (ed.). Pediatric surgery 6th edition. Elsevier, 2006;1255-1263.

23. Salö M, Ohlsson B, Arnbjörnsson E, Stenström P. Appendicitis in children from a gender perspective. Pediatr Surg Int. 2015 Sep;31(9):845-53.
24. Lukish J, Powell D, Morrow S, Cruess D, Guzzetta P. Laparoscopic appendectomy in children: use of the endoloop vs the endostapler. Arch Surg. 2007 Jan;142(1):58-62.

25. Centeno-Wolf N, Mircea L, Sanchez O, Genin B, Lironi A, Chardot C, Birraux J, Wildhaber BE. Long-term outcome of children with patent processus vaginalis incidentally diagnosed by laparoscopy. J Pediatr Surg. 2015 Nov;50(11):1898-902.

26. Song RY, Jung K. Drain insertion after appendectomy in children with perforated appendicitis based on a single-center experience. Ann Surg Treat Res. 2015 Jun;88(6):341-4.

27. Aneiros Castro B, Cano I, García A, Yuste P, Ferrero E, Gómez A. Abdominal Drainage After Laparoscopic Appendectomy in Children: An Endless Controversy? Scand J Surg. 2018 Sep;107(3):197-200.

28. Grewal H, Sweat J, Vazquez WD. Laparoscopic appendectomy in children can be done as a fast-track or same-day surgery. JSLS. 2004 Apr-Jun;8(2):151-4.

29. Rosenthal MG, Fakhry SM, Morse JL, Wyse RJ, Garland JM, et al. Where Did All the Appendicitis Go? Impact of the COVID-19 Pandemic on Volume, Management, and Outcomes of Acute Appendicitis in a Nationwide, Multicenter Analysis. Annals of Surgery. March 2021;2(1):pe048.

30. Ceresoli M, Coccolini F, Magnone S, Lucianetti A, Bisagni P, Armao T, Ansaloni L, Zago M, Chiarugi M, Catena F, Braga M; AppendicitisCOVID study group. The decrease of non-complicated acute appendicitis and the negative appendectomy rate during pandemic. Eur J Trauma Emerg Surg. 2021 Apr 12:1-7.

Conflict of interest: none declared Financial support: none declared 